\title{
FLI1 gene influences lesion size and skin test may predict therapeutic response in cutaneous leishmaniasis
}

\author{
Anadilton Santos da Hora ${ }^{1,2}$, Lucas Frederico de Almeida², Tainã Souza do Lago ${ }^{1,2}$, \\ Paulo Roberto Machado ${ }^{1,2,3}$, Léa Cristina Castellucci ${ }^{1,2,3 /+}$ \\ ${ }^{1}$ Universidade Federal da Bahia, Programa de Pós-Graduação em Ciências da Saúde, Salvador, BA, Brasil \\ ${ }^{2}$ Universidade Federal da Bahia, Serviço de Imunologia, Salvador, BA, Brasil \\ ${ }^{3}$ Instituto Nacional de Ciência e Tecnologia em Doenças Tropicais, Salvador, BA, Brasil
}

\begin{abstract}
Genes associated with wound healing have been shown to be risk factors for cutaneous leishmaniasis (CL) which is caused by Leishmania braziliensis. In this study, we examined whether the genes previously associated with CL influenced the clinical outcome. Patients were genotyped and retrospectively classified as responders, who were cured with a single course of pentavalent antimony (Sbv), or as refractories, who did not respond to Sbv. Patients characterised as responders showed a stronger response to the leishmanin skin test (LST) when compared to the refractory subjects $(\mathrm{p}=0.0003)$. Furthermore, we observed an association between the FLII CC genotype and an increased size of ulcers $(\mathrm{p}=0.0170)$. We suggest that the leishmanin skin test may be a predictive tool for therapeutic outcome and reinforce FLII as a potential influencer of susceptibility and lesion size in CL.
\end{abstract}

Key words: FLI7gene - therapeutic response - leishmaniasis

American cutaneous leishmaniasis (ACL) is a parasitic infectious disease caused by a protozoa of the genus Leishmania. It is one of the neglected diseases having greatest impact on public health due to its globalised distribution and limitations in diagnosis, treatment, and control in endemic foci. Pentavalent antimony (Sbv) has been the drug of first choice for the treatment of ACL. However, there have been cumulative reports of increased resistance to Sbv in different countries. ${ }^{(1,2)}$ Individuals refractory to the treatment with Sbv have a greater initial cutaneous lesion and require longer time to heal. ${ }^{(3)}$ A previous study has demonstrated the role of wound healing genes in the resolution of CL caused by Leishmania spp. ${ }^{(4)}$ The friend leukemia integration 1 (FLII) gene, initially identified as a gene controlling susceptibility of mice to Leishmania major infection, ${ }^{(5)}$ has been also associated with the development of human CL caused by Leishmania braziliensis. ${ }^{(6)}$ Furthermore, other lesion-healing genes linked to the FLII pathway have been also associated with ACL.(7) In this case study, we divided patients into responders and refractories based on their responses to the Sbv therapy to analyse the effects of single-nucleotide variants (SNVs), previously associated with $\mathrm{CL}$, on clinical parameters. One hundred and fifty-nine cases of CL were recruited from an endemic area of Corte de Pedra, Bahia, Brazil. The diagnosis of leishmaniasis was made through a clinical

doi: 10.1590/0074-02760190361

Financial support: This work was sponsored by the Programa de Pesquisa para o SUS (030/2014) and the National Institutes of Health (Grant Al 30639).

+ Corresponding author: leacastel@hotmail.com

(1) https://orcid.org/0000-0002-9625-2469

Received 27 September 2019

Accepted 31 January 2020 examination, a positive leishmanin skin test (LST) to the soluble Leishmania antigen, and by detection of the parasite's DNA through quantitative polymerase chain reaction (qPCR). Ethical approval was obtained from the IRB of the Federal University of Bahia (CEP-UFBA 22/2012) and the Brazilian National Ethical Committee (CONEP: 1258513.1.000.5537) for the use of clinical samples. Informed consent was obtained from the participants. Patients were recruited on admission at the health clinic. Blood samples were collected by venipuncture for genotyping. The patients were followed up until six months after treatment. Clinical data such as the response to treatment, the induration area for the skin test, and number and size of the ulcerated lesions were tabulated for analysis. Patients were classified as responders (controls) and refractories (cases) according to the following criteria: responders - individuals cured of CL after a single course of the Sbv standard treatment $(20 \mathrm{mg} / \mathrm{kg} /$ day for 20 days) with complete ulcer cicatrisation within 90 days; refractories - patients who needed two or more courses of Sbv or an alternative drug after failure of a single Sbv treatment. Supplementary results of participants have been described in Table I. Four SNVs [FLI1 (rs7930515), COL1A1 (rs2586488), $C T G F$ (rs6918698), and SMAD2 (rs1792658)] were genotyped by the TaqMan ${ }^{\circledR}$ qPCR technology (Thermo Fish$\mathrm{er}^{\mathbb{B}}$ ) using predesigned genotyping assays. Analysis of the association between the SNVs and the clinical data was performed by the non-parametric one-way ANOVA Kruskal Wallis or the Mann-Whitney $U$ tests using the GraphPad Prism software version 5. P values less than 0.05 were considered statistically significant. From the 159 patients, $54(33.96 \%)$ were the CL refractory cases compared to $105(66.04 \%)$ of the responders. We did not find significant associations between the genetic markers and the response to therapy (Table II). However, there was a strong association between the area of induration in the skin test (LST) and the treatment outcome, 
TABLE I

Clinical and epidemiological features of cutaneous leishmaniasis (CL) patients according to pentavalent antimony (Sbv) response

\begin{tabular}{|c|c|c|c|}
\hline \multirow[b]{2}{*}{ Clinical and demographic aspects } & \multicolumn{3}{|c|}{ Therapy response } \\
\hline & $\begin{array}{c}\text { Responders } \\
\mathrm{n}=105\end{array}$ & $\begin{array}{c}\text { Refractories } \\
n=54\end{array}$ & $\mathrm{p}$ value \\
\hline Age, mean $\pm \mathrm{SD}$ & $27.50 \pm 15.65$ & $27,29 \pm 17.18$ & 0,7920 \\
\hline \multicolumn{4}{|l|}{ Gender $(\%)$} \\
\hline Male & $67 / 105(63.80 \%)$ & $32 / 54(59.25 \%)$ & 0,6070 \\
\hline Number of lesions, median, (IQR) & $1(1-2)$ & $1(1-2)$ & 0,4659 \\
\hline Area of the greatest lesion, $\mathrm{mm}^{2}(\mathrm{IQR})$ & $120,0(32,5-217,0)$ & $132,5(30-412,5)$ & 0,2142 \\
\hline Area of Montenegro test, $\mathrm{mm}^{2}$ (IQR) & $300(180-419)$ & $195,5(110-292,8)$ & 0,0003 \\
\hline Lower limbs lesions (\%) & $72(66.74)$ & $32(13.76)$ & 0,3080 \\
\hline
\end{tabular}

SD: standard deviation; IQR: interquartile range.
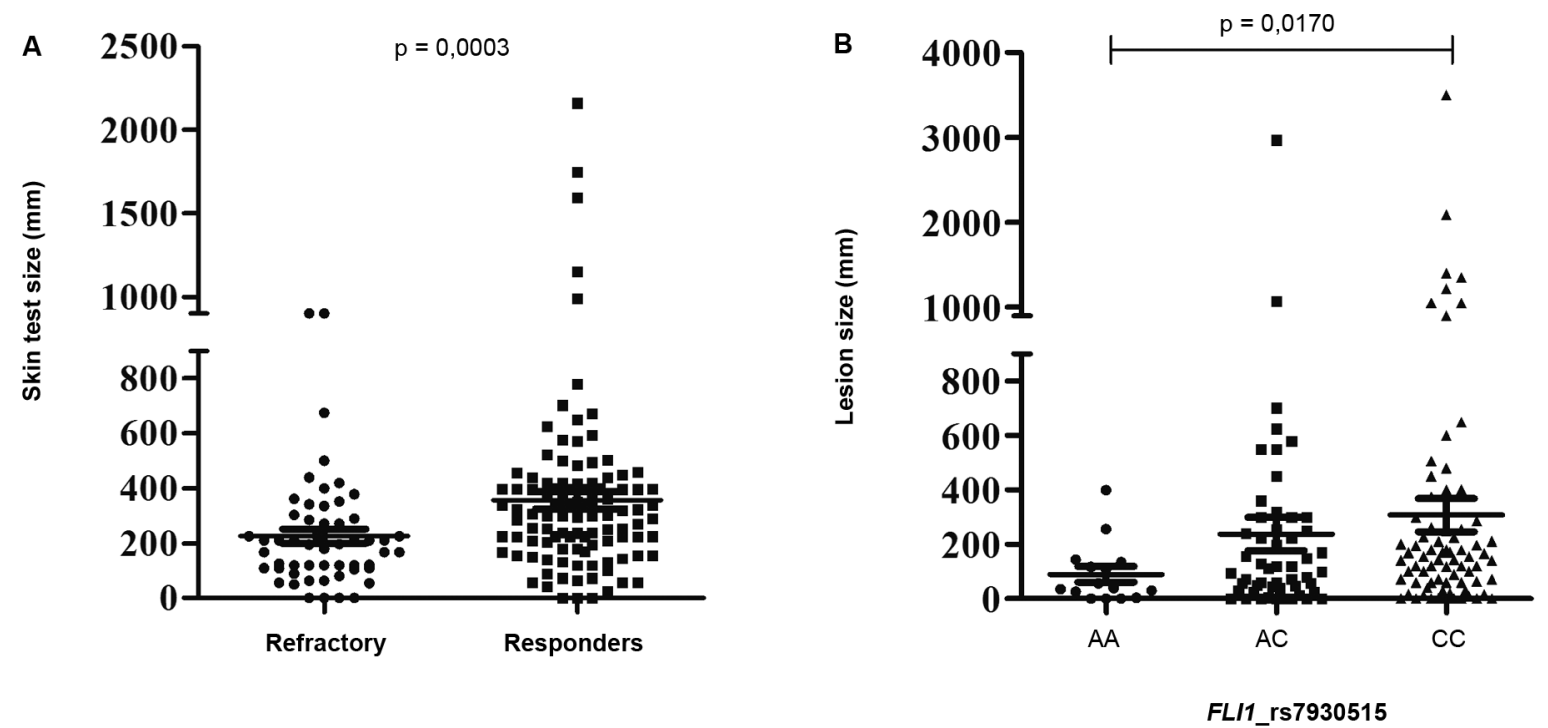

(A) Induration area $(\mathrm{mm})$ in the skin test of patients classified as refractories or responders according to the treatment with a pentavalent antimony. (B) Lesion size (mm) of patients with leishmaniasis according to the genotypes of the FLII gene.

with the test area being significantly larger in patients responding to $\mathrm{Sbv}(\mathrm{p}=0.0003)$, as shown in Figure (A). We also observed a strong association between the $\mathrm{CC}$ genotype of the FLII gene and the patient's lesion size, with larger lesions observed in the carriers of this genotype $(p=0.017)$, as shown in Figure (B). The CC genotype was less common ( $\mathrm{C}$ being the minor allele) and the frequencies were $11.3 \%$ and $5.1 \%$ in clinical cases and in controls, respectively. There were no significant associations between the markers and other parameters analysed.

The LST is one of the most common tests to diagnose $\mathrm{CL}$ as well as to confirm active or retrospective leishmaniasis in epidemiological surveys. ${ }^{(8)}$ Consistent with our results, a study in Brazil assessed the association between LST and therapeutic response and showed that the patients who did not respond to the treatment had less intense LST reactions than those who achieved clinical cure. For every $10 \mathrm{~mm}$ increase in size of the induration area in response to the skin test, there was $26 \%$ reduction in the probability of a treatment failure..$^{(9)}$ The greater induration area in responding patients may be attributed to their ability to develop an effective response in the early stages of infection by producing proinflammatory cytokines and reducing cytotoxic activity. Exacerbation of the cytotoxic activity has been reported to contribute to the increase in the number and duration of the lesions. ${ }^{(10)}$ Previous results have shown that the LST stimulates IFN- $\gamma$ production ${ }^{(11)}$ and this may be reflected in the ability of this group to get cured of the disease with a single course of treatment. Regarding the association between the CC genotype (rs7930515) at the FLII gene and the size of the lesions, the $\mathrm{C}$ allele has been previously reported to be associated with an increased susceptibility to the human $\mathrm{CL},{ }^{(6)}$ corroborating murine 
TABLE II

Logistic regression analysis between single-nucleotide polymorphisms (SNPs) and the pentavalent antimony (Sbv) response

\begin{tabular}{|c|c|c|c|}
\hline FLI1_rs7930515 & OR & $\mathrm{CI}$ & $\mathrm{p}$ \\
\hline Global 2df & & & 0.264 \\
\hline $\mathrm{A} / \mathrm{C} \times \mathrm{C} / \mathrm{C}$ & 0.748 & $0.383-1.461$ & 0.397 \\
\hline $\mathrm{A} / \mathrm{A} \times \mathrm{C} / \mathrm{C}$ & 2.105 & $0.551-8.041$ & 0.276 \\
\hline Global 1df & & & 0.754 \\
\hline Allele A & 1.080 & $0.662-1.763$ & 0.755 \\
\hline Allele C & 0.925 & $0.566-1.509$ & 0.755 \\
\hline likelihood-radio test & & & 0.109 \\
\hline COL1A1_rs2586488 & OR & CI & $\mathrm{p}$ \\
\hline Global 2df & & & 0.946 \\
\hline $\mathrm{A} / \mathrm{G} \times \mathrm{G} / \mathrm{G}$ & 1.079 & $0.565-2.058$ & 0.817 \\
\hline $\mathrm{A} / \mathrm{A} \times \mathrm{G} / \mathrm{G}$ & 0.922 & $0.319-2.662$ & 0.881 \\
\hline Global 1df & & & 0.994 \\
\hline Allele A & 1.001 & $0.623-1.608$ & 0.995 \\
\hline Allele G & 0.998 & $0.621-1.602$ & 0.995 \\
\hline likelihood-radio test & & & 0.739 \\
\hline CTGF_rs6918698 & OR & $\mathrm{CI}$ & $\mathrm{p}$ \\
\hline Global 2df & & & 0.858 \\
\hline $\mathrm{C} / \mathrm{G} \times \mathrm{G} / \mathrm{G}$ & 0.825 & $0.377-1.804$ & 0.631 \\
\hline $\mathrm{C} / \mathrm{C} \times \mathrm{G} / \mathrm{G}$ & 0.793 & $0.324-1.940$ & 0.612 \\
\hline Global 1df & & & 0.619 \\
\hline Allele C & 0.893 & $0.573-1.393$ & 0.620 \\
\hline Allele G & 1.118 & $0.717-1.743$ & 0.620 \\
\hline likelihood-radio test & & & 0.807 \\
\hline SMAD2_rs1792658 & OR & $\mathrm{CI}$ & $\mathrm{p}$ \\
\hline Global 2df & & & 0.554 \\
\hline $\mathrm{A} / \mathrm{C} \mathrm{X} \mathrm{C/C}$ & 0.553 & $0.156-1.961$ & 0.360 \\
\hline $\mathrm{A} / \mathrm{A} \times \mathrm{C} / \mathrm{C}$ & 0.729 & $0.212-2.502$ & 0.616 \\
\hline Global 1df & & & 0.900 \\
\hline Allele A & 1.031 & $0.637-1.667$ & 0.900 \\
\hline Allele C & 0.969 & $0.599-1.567$ & 0.900 \\
\hline likelihood-radio test & & & 0.280 \\
\hline
\end{tabular}

Global 2df: $p$ value at 2 degrees of freedom; Global 1df: $p$ value at 1 degree of freedom; OR: odds ratio; CI: 95\% confidence interval.

studies on $L$. major resistance. ${ }^{(5)}$ In this context, our data supported the role of FLII as an important gene involved in tissue repair mechanisms during human CL since the regulation of polymorphism of this gene is associated with a lesion formation. More functional studies need to be performed to evaluate the mechanisms of gene ex- pression in patients infected with L. braziliensis to determine their potential as influencers of the response to treatment and to explore their role as therapeutic targets.

\section{ACKNOWLEDGEMENTS}

To the physicians and staff of the Health Post of Corte de Pedra for their support in recruiting patients for this study.

\section{AUTHORS' CONTRIBUTION}

ASH, LFA and TSL performed the preparation of the samples, genotyping, and collection of the clinical data; PRM participated in the medical care of the patients and reviewed the final version of the manuscript; LCC supervised the laboratory work and undertook the responsibility of data interpretation and preparation of the manuscript. All authors read and approved the final manuscript. The authors declare that they have no commercial or financial relationships that may cause a potential conflict of interest.

\section{REFERENCES}

1. Sundar S, Jha TK, Thakur CP, Bhattacharya SK, Rai M. Oral miltefosine for the treatment of Indian visceral leishmaniasis. Trans R Soc Trop Med Hyg. 2006; 100(1): S26-33.

2. Prates FVO, Dourado MEF, Silva SC, Schriefer A, Guimarães LH, Brito MGO, et al. Fluconazole in the treatment of cutaneous leishmaniasis caused by Leishmania braziliensis: a randomized controlled trial. Clin Infect Dis. 2017; 64(1): 67-71.

3. Machado PR, Ampuero J, Guimarães LH, Villas boas L, Rocha AT, Schriefer A, et al. Miltefosine in the treatment of cutaneous leishmaniasis caused by Leishmania braziliensis in Brazil: a randomized and controlled trial. PLoS Negl Trop Dis. 2010; 4(12): e912.

4. Castellucci LC, Almeida LF, Jamieson SE, Fakiola M, Carvalho EM, Blackwell JM. Host genetic factors in American cutaneous leishmaniasis: a critical appraisal of studies conducted in an endemic area of Brazil. Mem Inst Oswaldo Cruz. 2014; 109(3): 279-88.

5. Sakthianandeswaren A, Curtis JM, Elso C, Kumar B, Baldwin TM, Lopaticki S, et al. Fine mapping of Leishmania major susceptibility locus $1 \mathrm{mr} 2$ and evidence of a role for Fli1 in disease and wound healing. Infect Immun. 2010; 78(6): 2734-44.

6. Castellucci LC, Jamieson SE, Miller EN, de Almeida LF, Oliveira J, Magalhaes A, et al. FLI1 polymorphism affects susceptibility to cutaneous leishmaniasis in Brazil. Genes Immun. 2011; 12(7): 589-94.

7. Castellucci LC, Jamieson SE, Almeida LF, Oliveira J, Guimaraes $\mathrm{LH}$, Lessa $\mathrm{M}$, et al. Wound healing genes and susceptibility to cutaneous leishmaniasis in Brazil. Infect Genet Evol. 2012; 12(5): 1102-10

8. Sessa PA, Falqueto A, Barros GCB, Varejão JBM. Resultados da reação de Montenegro em pacientes com leishmaniose tegumentar americana, autóctones do Estado do Espírito Santo. Rev Assoc Med Bras. 1991; 37: 115-8.

9. Antônio LD, Fagundes AT, Oliveira RD, Pinto PG, Bedoya-Pacheco SJ, Vasconcellos ED, et al. Montenegro skin test and age of skin lesion as predictors of treatment failure in cutaneous leishmaniasis. Rev Inst Med Trop Sao Paulo. 2014; 56(5): 375-80.

10. Novais FO, Carvalho AM, Clark ML, Carvalho LP, Beiting DP, Brodsky IE, et al. CD8+ T cell cytotoxicity mediates pathology in the skin by inflammasome activation and IL-1 $\beta$ production. PLoS Pathog. 2017; 13(2): e1006196.

11. José FF, da Silva IM, Araújo MI, Almeida RP, Bacellar O, Carvalho EM. Evaluation of the sensitization power of Montenegro skin test. Rev Soc Bras Med Trop. 2001; 34(6): 537-42. 